\title{
Mutagenicity of Analgesics, Their Derivatives, and Anti-inflammatory Drugs with S-9 Mix of Several Animal Species
}

\author{
Noboru KUBOYAMA and Akira FUJII
}

(Received 9 December 1991 and accepted 2 March 1992)

Key words: mutagenicity, analgesics, anti-inflammatory drugs, DNA damage, Ames test, Rec-assay

\begin{abstract}
An investigation was undertaken to determine whether analgesics and their derivatives (13 compounds), and anti-inflammatory drugs (4 compounds) had mutagenicity. Rec-assay was used to clarify specific DNA-damaging properties, and the Ames test was used to find back-mutations, using S-9 fractions obtained from the liver of 4 animal species pretreated with polychlorobiphenyl.

In the Rec-assay, salicylic acid $(2 \mathrm{mg})$, aspirin $(5 \mathrm{mg})$, benzoic acid $(4 \mathrm{mg})$, sulpyrine $(0.4 \mathrm{mg})$, indomethacin $(0.1 \mathrm{mg})$, oxyphenbutazone $(0.1 \mathrm{mg})$ and diclofenac sodium $(0.1 \mathrm{mg})$ showed a DNA-damaging tendency.

In the Ames test, mutagenicity of methyl salicylate was demonstrated using the Salmonella typhimurium TA98 strain upon addition of hamster S-9 mixture. Weak mutagenicity was also found using the TA100 strain with rat S-9 mixture for salicylic acid, sulpyrine, indomethacin and oxyphenbutazone, and with hamster S-9 mixture for methyl salicylate, acetaminophen and phenacetine.
\end{abstract}

\section{Introduction}

The mechanism of cancer induction has long been considered to be mutation caused by alteration of the primary structure of $\mathrm{DNA}^{[1,2]}$. In recent years, an almost linear relationship has been obtained between mutagenic potency determined by the Ames test and carcinogenic potency in animals. It has also been demonstrated by Ames and his colleagues that $90 \%$ of known human carcinogens are mutagenic ${ }^{[3,4]}$.

Therefore, from the viewpoint of careful and safe drug use, it is important to detect the mutagenicity of drugs. We have demonstrated previously that sulpyrine possesses the strongest mutagenicity among analgesic drugs in widespread use ${ }^{[5]}$.

On the other hand, the metabolic pathways of compounds, as well as their mutagenic potency, vary in mammalian species ${ }^{[6,7]}$. For example, it has been reported that mutagenicity of phenacetin, a component of many analgesic drugs, was detected in the TA100 system in the presence of liver S-9 from hamster, but not that from rat. Also, YAMAzoE et al. ${ }^{[7]}$ investigated the metabolic activation of 久保山 昇, 藤井 彰：Department of Pharmacology, Nihon University School of Dentistry at Matsudo

To whom all correspondence should be addressed: Dr. Noboru KUBOYAMA, Department of Pharmacology, Nihon University School of Dentistry at Matsudo, 2-870-1, Sakaecho-Nishi, Matsudo, Chiba 271, JAPAN. 
Trp-P-2 in 5 experimental animal species in order to clarify whether $\mathrm{N}$ hydroxylation was a common pathway for mutagenic activation, and to clarify the differences in activating enzymes among the species. In rats, the activity was low, and hepatic microsomes from hamster showed the highest activity, although there was no appreciable difference between the sexes. Therefore, S-9 mixes obtained from several species are an important factor for the efficient detection of mutagenicity ${ }^{[8,9]}$.

In this study, we tested various analgesics and their derivatives, and antiinflammatory drugs for mutagenic activity by metabolic activation of the compounds using rat, mouse, guinea pig, and hamster liver microsomes in the Recassay (cold-incubation method with Bacillus subtilis) in order to clarify their DNA-damaging capacity and mutagenicity, and using the Ames test with a slight modification with Salmonella typhimurium strains TA98 and TA100.

\section{Materials and Methods}

1. Chemicals

The structures of the analgesics, anti-inflammatory drugs and their derivatives are listed in Fig. 1.

Salicylic acid, sodium salicylate, aspirin, methyl salicylate, salicylamide, benzoic acid, acetanilide, acetaminophen, phenacetin, antipyrine, aminopyrine, sulpyrine (SP), and indomethacin were purchased from Wako Pure Chemical Industries, isopropylantipyrine (IPA) was from Nihon Roche Co., oxyphenbutazone and diclofenac sodium were from Fujisawa Pharmaceutical Co., Ltd., and naproxen was from Tanabe Co. NADP and G-6-P were purchased from Sigma Chemical Co. Furyl furamide (AF-2) was kindly supplied by Dr. T. Kada, National Institute of Genetics, Mishima, Japan. All other chemicals, reagents and solvents were purchased from Wako Pure Chemical Industries.

Benzopyrene (BP), 4-nitroquinoline-1-oxide (4NQO), mitomycin C (MMC; Kyowa Hakko Co.), and AF-2 were used as positive controls.

2. Bacterial strains

Bacillus subtilis strains H17 $\left(\operatorname{Rec}^{+}\right)$and M45 $\left(\operatorname{Rec}^{-}\right)$, used for the Rec-assay ${ }^{[10]}$, and Salmonella typhimurium strains TA98 and TA100, used for the mutation assay, Ames test ${ }^{[11,12]}$, were kindly provided by Dr. T. Kada of the National Institute of Genetics.

3. Rec-assay

Experimental procedures for the Rec-assay using the cold-incubation method were based mainly on those described already by KADA et al. ${ }^{[10]}$ Two strains of $B$. subtilis $\mathrm{H} 17$ and M45 were grown at $37^{\circ} \mathrm{C}$ in B-2 broth for $14 \mathrm{~h}$. Each culture was streaked on the dry surface of a B-2 agar plate in a standard Petri dish as shown in Fig. 2, taking care not to let them touch one another. Test compounds, $0.05 \mathrm{ml}$ $(0.25 \sim 5 \mathrm{mg} / \mathrm{disc})$, were dropped on a paper disc (diameter $8 \mathrm{~mm})$, which had been placed at the starting point of the streaks. All the plates were kept at $4^{\circ} \mathrm{C}$ for $24 \mathrm{~h}$, and then incubated at $37^{\circ} \mathrm{C}$ for $24 \mathrm{~h}$. The length of the inhibition zone was then measured $^{[13]}$.

When the inhibition zone of cellular growth was more than $2 \mathrm{~mm}$ of zone 
difference between growth inhibition zones for $\mathrm{Rec}^{+}$and $\mathrm{Rec}^{-}$strains, it was considered that the test compound had a damaging effect on cellular DNA (Fig.2).

Salicylate derivatives<smiles>O=C(O)c1ccccc1</smiles>

Salicylic acid

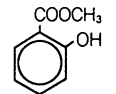

Methyl salicylate

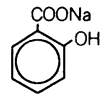

Sodium salicylate

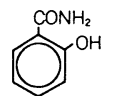

Salicylamide

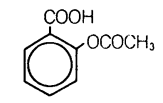

Aspirin

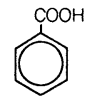

Benzoic acid

Aniline derivatives

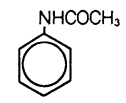

Acetanilide

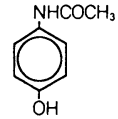

Acetaminophen

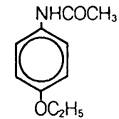

Phenacetin

Pyrazolone derivatives
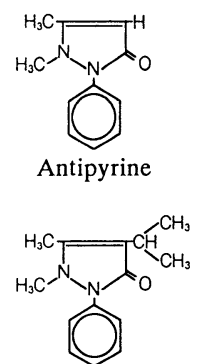

Isopropylantipyrine
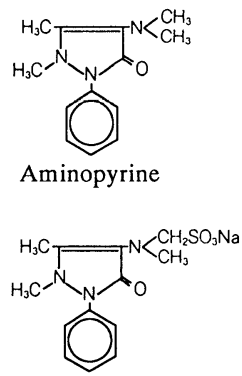

Sulpyline

Anti-inflammatory drugs

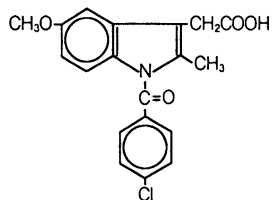

Indomethacin

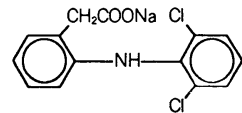

Diclofenac sodium

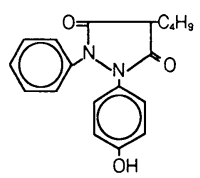

Oxyphenbutazone

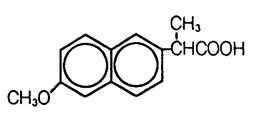

Naproxen

Fig. 1 Chemical structures and names of analgesics, their derivatives, and anti-inflammatory drugs 


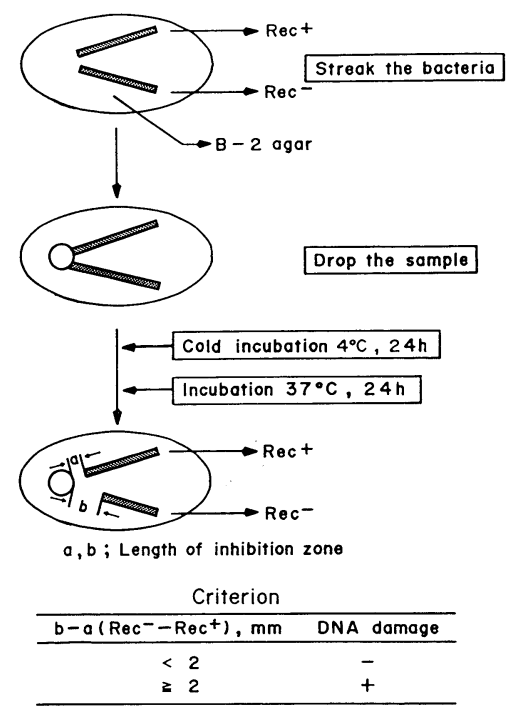

Fig. 2 Procedure for the Rec-assay (cold-incubation method) using Bacillus subtilis

4. Preparation of S-9 mix

S-9 mix was prepared in the following manner ${ }^{[11]}$ : SD-strain male rats, 7 weeks old, weighing 180 200 g, ddy-strain male mice, 7 weeks old, weighing $18 \sim 25 \mathrm{~g}$, Hartley-strain male guinea pigs, 5 weeks old, weighing $250 \sim 300 \mathrm{~g}$, and male golden hamsters, 5 weeks old, weighing $80 \sim 100$ g were obtained from Japan SLC Inc. Polychlorobiphenyl (PCB) was dissolved in corn oil and administered once to all the animals intraperitoneally at a dose of $500 \mathrm{mg} / \mathrm{kg}, 5$ days before liver extraction.

The S-9 fraction was prepared aseptically by centrifugation of a liver homogenate $\left(25 \%\right.$ in $0.15 \mathrm{M} \mathrm{KCl}$ ) at $4^{\circ} \mathrm{C}$ and $9,000 \times \mathrm{g}$ for $30 \mathrm{~min}$, as described by AmEs et al. ${ }^{[11]}$

\section{Ames test}

The Salmonella/microsome mutagenicity test was carried out according to the procedure reported by AMEs et al. ${ }^{[11,12]}$, with a slight modification. The test compounds, freshly dissolved in $0.1 \mathrm{ml}(0.1 \sim 10 \mathrm{mg} /$ plate $)$ of DMSO, were preincubated at $37^{\circ} \mathrm{C}$ for $30 \mathrm{~min}$ in a shaking water bath with $0.5 \mathrm{ml}$ of $1 / 15 \mathrm{M}$ phosphate buffer ( $\mathrm{pH} 7.4$ ) or $0.5 \mathrm{ml} \mathrm{S}-9 \mathrm{mix}$ and $0.1 \mathrm{ml}$ of bacterial culture, as shown in Fig. 3. Then $3 \mathrm{ml}$ of soft agar $\left(45^{\circ} \mathrm{C}\right)$ was added by vortex action and the mixture was poured onto the surface of a minimal agar plate of Vogel-Bonner $\mathrm{E}$ medium ( $1.5 \%$ agar, $2 \%$ glucose). The plates were incubated at $37^{\circ} \mathrm{C}$ in the dark for $48 \mathrm{~h}$, then $\mathrm{His}^{+}$revertant colonies were counted. Test compounds inducing more than twice the number of $\mathrm{His}^{+}$revertant colonies than that due to spontaneous mutation were considered to be mutagenic. 


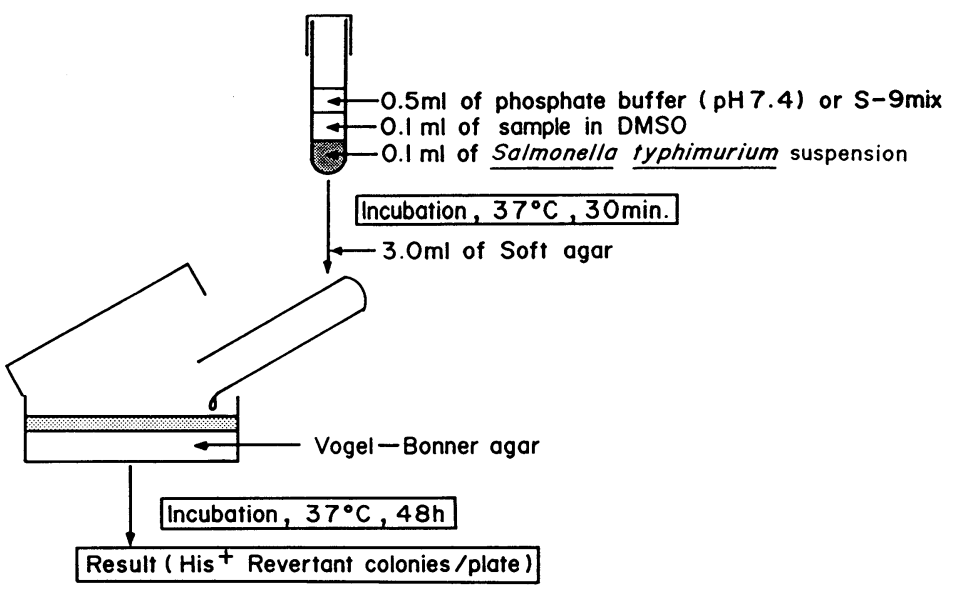

Fig. 3 procedure for the Ames test using Salmonella typhimurium TA98 and TA100

\begin{abstract}
Results
1. Rec-assay

The results of the Rec-assay using the cold-incubation method for analgesics and their derivatives (13 samples), and anti-inflammatory drugs (4 samples) are shown in Table 1. The dose-response curves of salicylate derivatives (4 samples) are shown in Fig. 4. A trend of weak DNA damage was demonstrated by salicylic acid (more than $2 \mathrm{mg}$ ), aspirin (more than $5 \mathrm{mg}$ ) and benzoic acid (more than 4 $\mathrm{mg}$ ), but methylsalicylate was negative. Salicylic acid was the most potent mutagenic compound among the salicylate derivatives.

Aniline derivatives such as acetanilide, acetaminophen and phenacetin had no DNA-damaging property at doses of $0.02 \sim 5 \mathrm{mg} /$ disc. Among the pyrazolone derivatives, antipyrine, aminopyrine and IPA induced no DNA damage. SP was found to induce DNA damage at doses above $0.4 \mathrm{mg} / \mathrm{plate}$, and the dose-response curve was nearly linear (Fig. 5).

The results for indomethacin, oxyphenbutazone and diclofenac sodium showed some representative differences in the inhibition zone at doses above 0.1 $\mathrm{mg} / \mathrm{disc}$ in the Rec-assay. However, since both $\mathrm{Rec}^{+}$and $\mathrm{Rec}^{-}$strains showed growth inhibition, these compounds were thought to have possible cytotoxicity at concentrations higher than $1 \mathrm{mg} /$ disc (Fig. 6).
\end{abstract}


Table 1 Rec-assay on analgesics, their derivatives, and anti-inflammatory drugs

\begin{tabular}{|c|c|c|c|c|}
\hline \multirow{2}{*}{ Compound } & \multirow{2}{*}{$\begin{array}{c}\text { Dose } \\
\mathrm{mg} / \text { disc }\end{array}$} & \multicolumn{2}{|c|}{ Length of inhibition zone, $\mathrm{mm}$} & \multirow{2}{*}{$\begin{array}{c}\text { Differnce, mm } \\
\left(\mathrm{Rec}^{-}-\mathrm{Rec}^{+}\right)\end{array}$} \\
\hline & & $\mathrm{H} 17\left(\mathrm{Rec}^{+}\right)$ & M45 $\left(\mathrm{Rec}^{-}\right)$ & \\
\hline Control (DMSO) & 0 & $0.0 \pm 0.0$ & $0.0 \pm 0.0$ & $0.0 \pm 0.0$ \\
\hline \multicolumn{5}{|l|}{ Salicylate derivatives } \\
\hline Salicylic acid & 5 & $2.7 \pm 0.6$ & $7.3 \pm 1.4$ & $4.7 \pm 1.2^{*}$ \\
\hline $\mathrm{Na}$ salicylate & 5 & $0.0 \pm 0.0$ & $0.0 \pm 0.0$ & $0.0 \pm 0.0$ \\
\hline Aspirin & 5 & $2.1 \pm 0.3$ & $4.5 \pm 0.2$ & $2.4 \pm 0.2^{*}$ \\
\hline Me. salicylate & 5 & $0.0 \pm 0.0$ & $1.2 \pm 0.3$ & $1.2 \pm 0.3$ \\
\hline Salicylamide & 5 & $0.0 \pm 0.0$ & $0.0 \pm 0.0$ & $0.0 \pm 0.0$ \\
\hline Benzoic acid & 5 & $1.5 \pm 0.2$ & $4.3 \pm 0.3$ & $2.9 \pm 0.5^{*}$ \\
\hline \multicolumn{5}{|l|}{ Aniline derivatives } \\
\hline Acetanilide & 5 & $0.0 \pm 0.0$ & $0.0 \pm 0.0$ & $0.0 \pm 0.0$ \\
\hline Acetaminophen & 5 & $0.0 \pm 0.0$ & $0.0 \pm 0.0$ & $0.0 \pm 0.0$ \\
\hline Phenacetin & 5 & $0.0 \pm 0.0$ & $0.0 \pm 0.0$ & $0.0 \pm 0.0$ \\
\hline \multicolumn{5}{|l|}{ Pyrazolone derivatives } \\
\hline Antipyrine & 5 & $0.0 \pm 0.0$ & $0.0 \pm 0.0$ & $0.0 \pm 0.0$ \\
\hline Aminopyrine & 5 & $0.0 \pm 0.0$ & $0.0 \pm 0.0$ & $0.0 \pm 0.0$ \\
\hline IPA & 5 & $0.0 \pm 0.0$ & $0.0 \pm 0.0$ & $0.0 \pm 0.0$ \\
\hline Sulpyrine & 5 & $0.0 \pm 0.0$ & $21.5 \pm 0.7$ & $21.5 \pm 0.7 *$ \\
\hline \multicolumn{5}{|c|}{ Anti-inflammatory drugs } \\
\hline Indomethacin & 5 & $8.3 \pm 0.3$ & $12.8 \pm 0.8$ & $4.5 \pm 0.6^{*}$ \\
\hline Oxyphenbutazone & 5 & $12.5 \pm 0.5$ & $15.7 \pm 0.1$ & $3.2 \pm 0.3^{*}$ \\
\hline Diclofenac $\mathrm{Na}$ & 5 & $4.7 \pm 1.3$ & $12.7 \pm 1.6$ & $8.0 \pm 1.7^{*}$ \\
\hline Naproxen & 5 & $0.0 \pm 0.0$ & $0.0 \pm 0.0$ & $0.0 \pm 0.0$ \\
\hline \multicolumn{5}{|l|}{ Positive control $(\mu \mathrm{g})$} \\
\hline 4NQO & 0.2 & $0.0 \pm 0.0$ & $25.1 \pm 3.1$ & $25.1 \pm 3.1^{*}$ \\
\hline MMC & 0.1 & $1.1 \pm 0.2$ & $10.2 \pm 2.1$ & $9.1 \pm 1.3^{*}$ \\
\hline
\end{tabular}

* More than $2 \mathrm{~mm}$ zone difference

Mean $\pm \mathrm{SD}$ for 5 plates, $\mathrm{mm}$

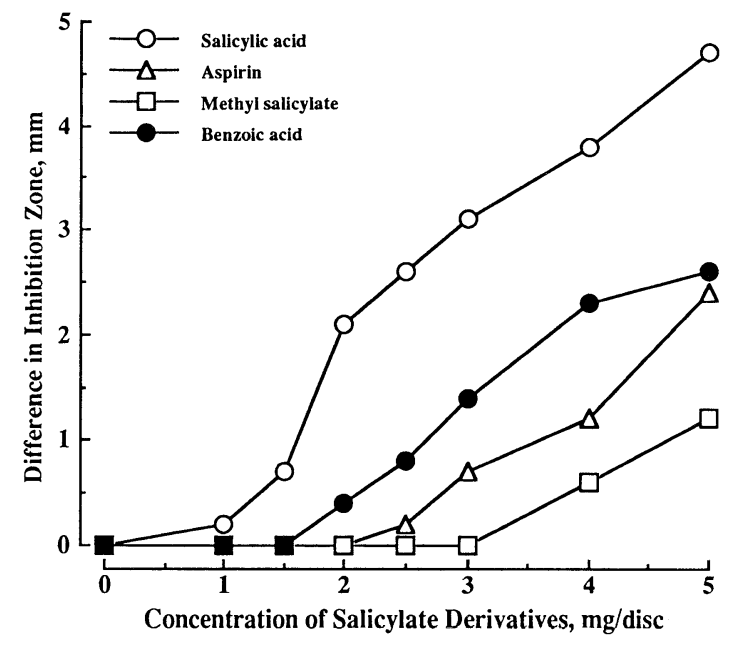

Fig. 4 Rec-assay on salicylate derivatives 


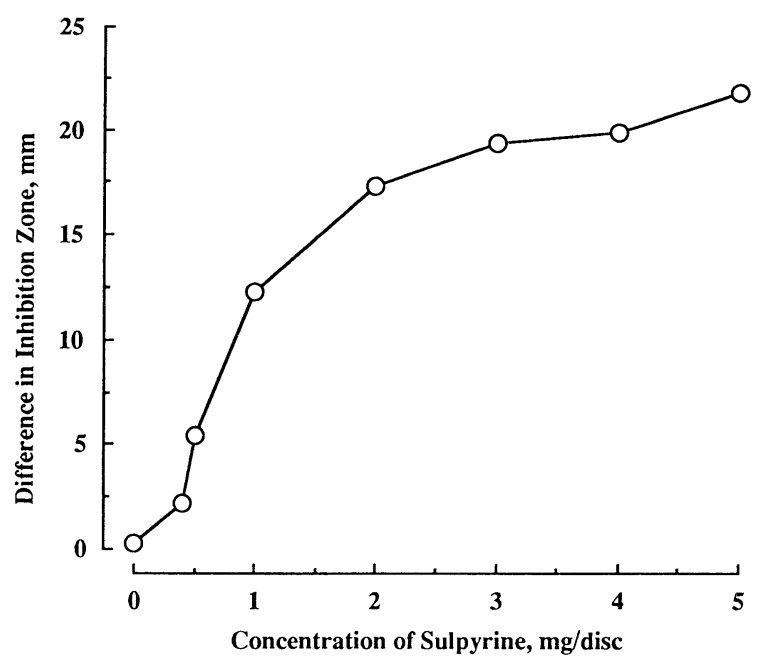

Fig. 5 Rec-assay on sulpyrine

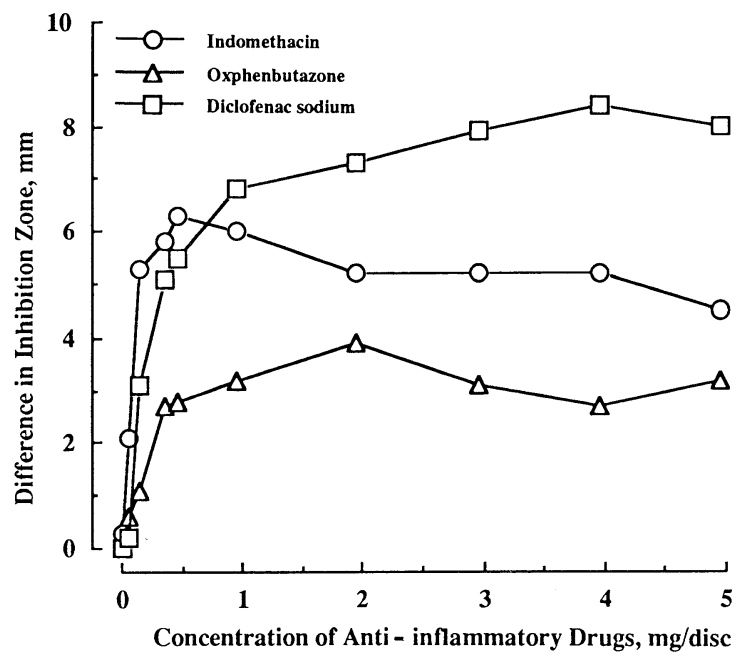

Fig. 6 Rec-assay on anti-inflammatory drugs 


\section{Ames test}

The results of the Ames test on $\mathrm{His}^{+}$revertant colonies/plate using the TA98 system in the presence of S-9 mix obtained from the liver of rat, mouse, guinea pig or hamster are summarized in Table 2. Mutagenicity was demonstrated only for methyl salicylate using strain TA98 upon addition of S-9 mix from hamster.

Acetanilide, acetaminophen and phenacetin at doses of $0.1 \sim 10 \mathrm{mg} / \mathrm{plate}$, did not induce $\mathrm{His}^{+}$revertant colonies in the presence of S-9 mix obtained from the liver of all animal species.

All pyrazolone derivatives and anti-inflammatory drugs tested did not induce $\mathrm{His}^{+}$revertant colonies in the presence or absence of S-9 mix obtained from the liver of all animal species.

4NQO, AF-2 and BP were used as the positive controls for the Ames test on $\mathrm{His}^{+}$revertant colonies of TA98. For example, among 4 animal species, rat was most effective for increasing the number of $\mathrm{His}^{+}$revertant colonies, at $234 \pm 66$ with $5 \mu \mathrm{g} /$ plate BP, the order being rat $>$ mouse $>$ hamster $>$ guinea pig.

Table 2 Ames test, reversion of Salmonella typhimurium TA98 induced by analgesics, their derivatives, and anti-inflammatory drugs

\begin{tabular}{|c|c|c|c|c|c|c|}
\hline \multirow{3}{*}{ Compound } & \multirow{3}{*}{$\begin{array}{c}\text { Dose } \\
\mathrm{mg} / \text { disc }\end{array}$} & \multirow{3}{*}{$-S-9$} & \multicolumn{4}{|c|}{ His $^{+}$revertant colonies/plate } \\
\hline & & & \multicolumn{4}{|c|}{$+S-9$} \\
\hline & & & Rat & Mouse & G. pig & Hamster \\
\hline Control (DMSO) & 0 & $24 \pm 3$ & $42 \pm 6$ & $28 \pm 3$ & $36 \pm 5$ & $38 \pm 7$ \\
\hline \multicolumn{7}{|l|}{ Salicylate derivatives } \\
\hline Salicylic acid & 0.1 & $0 \pm 0$ & $19 \pm 3$ & $21 \pm 3$ & $31 \pm 2$ & $42 \pm 5$ \\
\hline Na salicylate & 0.1 & $13 \pm 2$ & $23 \pm 2$ & $29 \pm 6$ & $23 \pm 1$ & $39 \pm 4$ \\
\hline Aspirin & 0.1 & $17 \pm 3$ & $31 \pm 2$ & $35 \pm 3$ & $27 \pm 3$ & $48 \pm 5$ \\
\hline Me. salicylate & 0.1 & $0 \pm 0$ & $24 \pm 3$ & $36 \pm 6$ & $36 \pm 5$ & $74 \pm 4^{*}$ \\
\hline Salicylamide & 0.1 & $17 \pm 4$ & $31 \pm 3$ & $29 \pm 2$ & $26 \pm 3$ & $40 \pm 6$ \\
\hline Benzoic acid & 0.1 & $0 \pm 0$ & $33 \pm 4$ & $26 \pm 7$ & $33 \pm 4$ & $28 \pm 6$ \\
\hline \multicolumn{7}{|l|}{ Aniline derivatives } \\
\hline Acetanilide & 0.1 & $18 \pm 2$ & $23 \pm 2$ & $36 \pm 1$ & $35 \pm 3$ & $45 \pm 2$ \\
\hline Acetaminophen & 0.1 & $19 \pm 4$ & $29 \pm 6$ & $14 \pm 1$ & $23 \pm 7$ & $30 \pm 2$ \\
\hline Phenacetin & 0.1 & $28 \pm 4$ & $21 \pm 1$ & $19 \pm 0$ & $39 \pm 7$ & $41 \pm 1$ \\
\hline \multicolumn{7}{|l|}{ Pyrazolone derivatives } \\
\hline Antipyrine & 1.0 & $18 \pm 2$ & $25 \pm 5$ & $38 \pm 4$ & $34 \pm 3$ & $45 \pm 3$ \\
\hline Aminopyrine & 1.0 & $16 \pm 2$ & $30 \pm 4$ & $33 \pm 2$ & $29 \pm 5$ & $35 \pm 5$ \\
\hline IPA & 1.0 & $11 \pm 0$ & $21 \pm 5$ & $22 \pm 4$ & $28 \pm 3$ & $39 \pm 5$ \\
\hline Sulpyrine & 1.0 & $32 \pm 8$ & $49 \pm 3$ & $52 \pm 2$ & $54 \pm 2$ & $45 \pm 6$ \\
\hline \multicolumn{7}{|c|}{ Anti-infllmmatory drugs } \\
\hline Indomethacin & 0.1 & $28 \pm 3$ & $38 \pm 6$ & $20 \pm 2$ & $37 \pm 3$ & $36 \pm 3$ \\
\hline Oxyphenbutazone & 0.1 & $13 \pm 1$ & $31 \pm 5$ & $43 \pm 5$ & $41 \pm 5$ & $31 \pm 3$ \\
\hline Diclofenac $\mathrm{Na}$ & 0.1 & $16 \pm 2$ & $33 \pm 4$ & $29 \pm 8$ & $33 \pm 6$ & $46 \pm 5$ \\
\hline Naproxen & 0.1 & $21 \pm 6$ & $38 \pm 6$ & $37 \pm 8$ & $41 \pm 2$ & $39 \pm 2$ \\
\hline \multicolumn{7}{|l|}{ Positive control $(\mu \mathrm{g})$} \\
\hline 4NQO & 0.5 & $482 \pm 34^{*}$ & $21 \pm 5$ & $33 \pm 3$ & $26 \pm 3$ & $31 \pm 3$ \\
\hline$A F-2$ & 0.02 & $240 \pm 31^{*}$ & $79 \pm 11$ & $80 \pm 21^{*}$ & $102 \pm 22 *$ & $67 \pm 11$ \\
\hline $\mathrm{BP}$ & 5.0 & $31 \pm 6$ & $234 \pm 66^{*}$ & $81 \pm 39^{*}$ & $123 \pm 36^{*}$ & $165 \pm 45^{*}$ \\
\hline
\end{tabular}

* More than twice the number of $\mathrm{His}^{+}$revertants than that due to spontaneous mutation Mean \pm SD for 5 plates 
The results of the Ames test in terms of the numbers of $\mathrm{His}^{+}$revertant colonies/plate of TA100 in the presence of S-9 mix obtained from 4 animal species are summarized in Table 3.

Salicylic acid $(0.1 \mathrm{mg})$ produced $446 \pm 78 \mathrm{His}^{+}$revertant colonies upon addition of S-9 mix obtained from rat. The number of $\mathrm{His}^{+}$revertant colonies observed in the presence of methyl salicylate $(0.1 \mathrm{mg})$ was $400 \pm 41$ upon addition of S-9 mix obtained from hamster. Weak mutagenicity was demonstrated by acetaminophen in the presence of S-9 mix obtained from hamster. Phenacetin $(0.1 \mathrm{mg})$ gave $400 \pm$ 78 and $410 \pm 33 \mathrm{His}^{+}$revertant colonies after addition of S-9 mix obtained from guinea pig and hamster, respectively (Fig. 7). Weak mutagenicity was demonstrated for sulpyrine $(5 \mathrm{mg})$ with rat S-9 mix.

Faint mutagenicity was also found for indomethacin and oxyphenbutazone upon addition of S- 9 mix obtained from rat. All other drugs were negative. 4NQO,

Table 3 Ames test, reversion of Salmonella typhimurium TA100 induced by analgesics, their derivatives, and anti-inflammatory drugs

\begin{tabular}{|c|c|c|c|c|c|c|}
\hline \multirow{3}{*}{ Compound } & \multirow{3}{*}{$\begin{array}{c}\text { Dose } \\
\mathrm{mg} / \text { disc }\end{array}$} & \multirow{3}{*}{$-S-9$} & \multicolumn{4}{|c|}{$\mathrm{His}^{+}$revertant colonies/plate } \\
\hline & & & \multirow[b]{2}{*}{ Rat } & \multicolumn{2}{|c|}{$+\mathrm{S}-9$} & \multirow[b]{2}{*}{ Hamster } \\
\hline & & & & Mouse & G. pig & \\
\hline Control (DMSO) & 0 & $141 \pm 31$ & $160 \pm 33$ & $158 \pm 51$ & $161 \pm 13$ & $182 \pm 33$ \\
\hline \multicolumn{7}{|l|}{ Salicylate derivatives } \\
\hline Salicylic acid & 0.1 & $198 \pm 71$ & $446 \pm 78^{*}$ & $161 \pm 45$ & $170 \pm 31$ & $150 \pm 11$ \\
\hline Na salicylate & 0.1 & $130 \pm 30$ & $110 \pm 37$ & $89 \pm 11$ & $180 \pm 25$ & $150 \pm 38$ \\
\hline Aspirin & 0.1 & $120 \pm 20$ & $100 \pm 30$ & $150 \pm 15$ & $122 \pm 30$ & $113 \pm 21$ \\
\hline Me. salicylate & 0.1 & $202 \pm 61$ & $200 \pm 22$ & $198 \pm 27$ & $150 \pm 43$ & $400 \pm 41^{*}$ \\
\hline Salicylamide & 0.1 & $150 \pm 54$ & $199 \pm 71$ & $200 \pm 43$ & $120 \pm 50$ & $207 \pm 64$ \\
\hline Benzoic acid & 0.1 & $78 \pm 31$ & $199 \pm 68$ & $217 \pm 48$ & $130 \pm 10$ & $120 \pm 31$ \\
\hline \multicolumn{7}{|l|}{ Aniline derivatives } \\
\hline Acetanilide & 0.1 & $150 \pm 34$ & $167 \pm 10$ & $180 \pm 20$ & $177 \pm 31$ & $222 \pm 43$ \\
\hline Acetaminophen & 0.1 & $190 \pm 54$ & $200 \pm 11$ & $190 \pm 23$ & $195 \pm 19$ & $380 \pm 70^{*}$ \\
\hline Phenacetin & 0.1 & $183 \pm 21$ & $240 \pm 31$ & $182 \pm 33$ & $400 \pm 78^{*}$ & $410 \pm 33^{*}$ \\
\hline \multicolumn{7}{|l|}{ Pyrazolone derivatives } \\
\hline Antipyrine & 1.0 & $170 \pm 11$ & $149 \pm 18$ & $150 \pm 49$ & $160 \pm 32$ & $200 \pm 22$ \\
\hline Aminopyrine & 1.0 & $155 \pm 22$ & $167 \pm 23$ & $125 \pm 29$ & $133 \pm 51$ & $191 \pm 51$ \\
\hline IPA & 1.0 & $155 \pm 36$ & $170 \pm 66$ & $166 \pm 31$ & $145 \pm 40$ & $172 \pm 34$ \\
\hline Sulpyrine & 5.0 & $150 \pm 28$ & $366 \pm 68^{*}$ & $168 \pm 39$ & $155 \pm 33$ & $200 \pm 30$ \\
\hline \multicolumn{7}{|c|}{ Anti-inflammatory drugs } \\
\hline Indomethacin & 0.1 & $250 \pm 58$ & $410 \pm 85^{*}$ & $152 \pm 32$ & $200 \pm 24$ & $201 \pm 25$ \\
\hline Oxyphenbutazone & 0.1 & $170 \pm 66$ & $392 \pm 29^{*}$ & $182 \pm 22$ & $150 \pm 19$ & $168 \pm 29$ \\
\hline Diclofenac $\mathrm{Na}$ & 0.1 & $16 \pm 2$ & $33 \pm 4$ & $29 \pm 8$ & $33 \pm 6$ & $46 \pm 5$ \\
\hline Naproxen & 0.1 & $21 \pm 6$ & $38 \pm 6$ & $37 \pm 8$ & $41 \pm 2$ & $39 \pm 2$ \\
\hline \multicolumn{7}{|l|}{ Positive control $(\mu \mathrm{g})$} \\
\hline \multirow[t]{2}{*}{ 4NQO } & 0.5 & $1233^{*}$ & $480^{*}$ & $517^{*}$ & $766^{*}$ & $500^{*}$ \\
\hline & & \pm 216 & \pm 78 & \pm 116 & \pm 163 & \pm 138 \\
\hline \multirow[t]{2}{*}{$\mathrm{AF}-2$} & 0.02 & $1700^{*}$ & $576^{*}$ & $539^{*}$ & $685^{*}$ & $780^{*}$ \\
\hline & & \pm 263 & \pm 103 & \pm 113 & \pm 186 & \pm 261 \\
\hline \multirow[t]{2}{*}{$\mathrm{BP}$} & 5.0 & 180 & $1350^{*}$ & $517^{*}$ & $1100^{*}$ & $850^{*}$ \\
\hline & & \pm 36 & \pm 186 & \pm 134 & \pm 267 & \pm 161 \\
\hline
\end{tabular}

* More than twice the number of $\mathrm{His}^{+}$revertants than that due to spontaneous mutation Mean \pm SD for 5 plates 
AF-2 and BP were used as the positive controls. For BP, among the 4 animal species, rat was most effective, increasing the number of $\mathrm{His}^{+}$revertant colonies to $1350 \pm 281$, and giving an order of rat $>$ guinea pig $>$ hamster $>$ mouse.

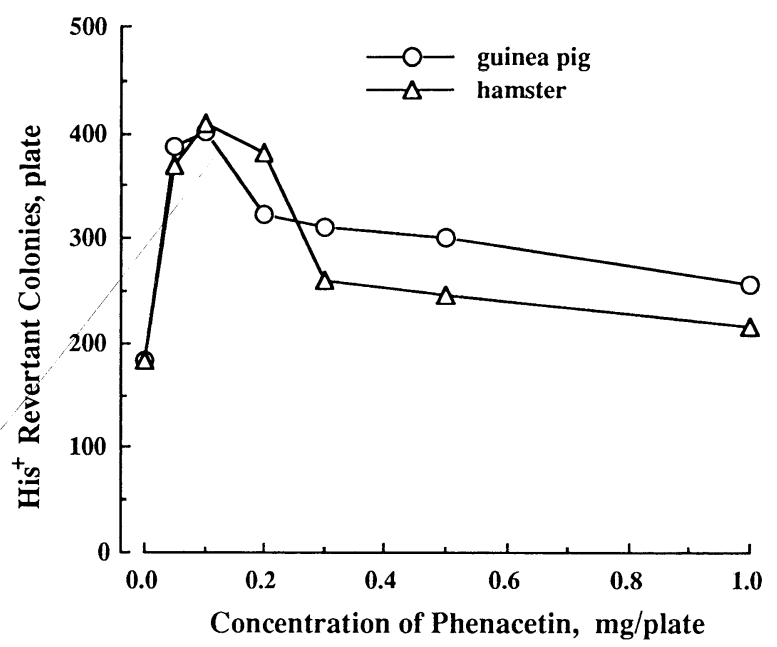

Fig. 7 Effect on S-9 fractions obtained from PCB-treated guinea pig and hamster on mutagenicity of phenacetin in TA100

\section{Discussion}

We investigated whether widely used analgesics, their derivatives, and antiinflammatory drugs possessed mutagenicity.

A trend of weak DNA damage was demonstrated for salicylic acid, which was the most potent DNA-damaging compound among the salicylate derivatives. Modification of the $-\mathrm{COOH}$ and $-\mathrm{OH}$ groups of salicylic acid decreased this DNA-damaging potency. Mutagenicity for salicylic acid was found by the Ames test using strain TA100 in the presence of S-9 mix obtained from rat, and for methyl salicylate using strains TA98 and TA100 in the presence of S-9 mix obtained from hamster. Several investigators ${ }^{[14,15]}$ have reported that all salicylate derivatives are teratogenic and show fetal toxicity in various animals. There is also evidence that aspirin causes congenital malformation in $\operatorname{man}^{[16]}$.

It may be concluded from the results of the present study and those by other investigators ${ }^{[14-16]}$ that salicylic acid, aspirin and methyl salicylate are potentially carcinogenic compounds.

Phenacetin and its metabolite acetaminophen cause serious side effects, such as renal papillary necrosis ${ }^{[17-19]}$, and phenacetin has been reported to produce tumors in the renal pelvis and urinary bladder of rats ${ }^{[20]}$. In another case, IsAKA et al. ${ }^{[21]}$ described that the target of phenacetin-induced carcinogenesis was the nasal cavity and urinary tract. Sugimura et al. ${ }^{[22]}$, using strains TA98 and TA100 with 
or without S-9 mix, reported that phenacetin itself had no mutagenicity. On the other hand, NoHmI et al. ${ }^{[9]}$ reported that phenacetin was clearly mutagenic in the TA100 system when S-9 mix from PCB-treated hamster instead of rat was used, and that phenacetin mutagenicity was due to the difference in deacetylation activity between rat and hamster liver microsomes.

In the present study, phenacetin and acetaminophen had no DNA-damaging capacity in the Rec-assay, but phenacetin showed mutagenicity to TA100 with S-9 mix obtained from guinea pig and hamster, and acetaminophen was mutagenic to TA100 in the presence of S-9 mix from hamster. Among the 4 animal species, hamster was the most effective in increasing the number of $\mathrm{His}^{+}$revertant colonies $(410 \pm 33)$ for phenacetin at $0.1 \mathrm{mg} /$ plate, giving the order: hamster $>$ guinea pig $>$ rat $>$ mouse.

LIJINSKY et al. ${ }^{[23]}$ reported that several drugs containing secondary and tertiary amine groups reacted with sodium nitrite in vitro and in vivo, yielding $\mathrm{N}$-nitroso compounds. For example, dimethylnitrosoamine (DMN) was readily formed from aminopyrine and nitrite in rat stomach, and caused hemorrhagic liver tumors in rats $^{[24]}$. On the other hand, ARISAwA et al. ${ }^{[25]}$ reported that at a concentration of 0.1 $\sim 10 \mathrm{mg} / \mathrm{ml}$ and $\mathrm{pH} 1.5 \sim 4.5$, antipyrine, aminopyrine and SP, but not IPA, were easily reactive with equal or 2 -fold amounts of sodium nitrite to give various nitrosation products.

In this study, antipyrine, aminopyrine, IPA and SP were clearly demonstrated to have DNA-damaging properties at doses of more than $0.4 \mathrm{mg} /$ disc by Rec-assay, with an almost linear dose-response curve. SP showed mutagenicity using the TA100 system with rat S-9 mix, but not with TA98. Kuboy AmA ${ }^{[26]}$ has already reported that SP and its metabolites have mutagenicity.

\section{Conclusions}

In order to study the mutagenicity of analgesics, their derivatives, and antiinflammatory drugs, the Rec-assay (cold-incubation method) and Ames test were performed. In the Rec-assay, Bacillus subtilis $\mathrm{H}-17\left(\mathrm{Rec}^{+}\right)$and $\mathrm{M}-45\left(\mathrm{Rec}^{-}\right)$strains were used to assess the presence of DNA-damaging potential. In the Ames test, Salmonella typhimurium strains TA98 and TA100 were used to reveal backmutation:

Salicylate derivatives, salicylic acid ( $2 \mathrm{mg}$ ), aspirin $(5 \mathrm{mg})$, and benzoic acid (4 $\mathrm{mg}$ ) showed specific DNA-damaging properties in the Rec-assay. Methyl salicylate reacted with strain TA98 in the presence of hamster S-9 mix, and salicylic acid and methyl salicylate were also demonstrated to be mutagenic using strain TA100 with S-9 mix from rat and hamster.

Weak mutagenicity was demonstrated by acetaminophen and phenacetine with hamster S-9 mix and by phenacetine with guinea pig S-9 mix in the Ames test.

All pyrazolone derivatives except SP produced no DNA damage or mutagenicity under the present experimental conditions. The dose-DNA damage curve for SP was nearly linear. Weak mutagenicity of SP was also found using strain TA100 with S-9 mix of rat.

When indomethacin, oxyphenbutazone and diclofenac sodium were tested, 
not only the $\operatorname{Rec}^{-}$- strain but also $\operatorname{Rec}^{+}$was affected at doses of more than $0.1 \mathrm{mg} /$ disc, indicating that these drugs possessed strong cytotoxicity. In the Ames test, mutagenicity was demonstrated for indomethacin $(0.1 \mathrm{mg})$ and oxyphenbutazone $(0.1 \mathrm{mg})$ using strain TA100 with rat S-9 mix. Therefore, care should be taken with prolonged administration of salicylic acid, methyl salicylate, acetaminophen, phenacetin, SP, indomethacin, oxyphenbutazone and diclofenac sodium.

\section{Refernces}

[1] Brookes, P.: Quantitative aspects of the reaction of some carcinogens with nucleic acids and the possible significance of such reactions in the process of carcinogenesis, Cancer Res., 26, 1994-2003, 1966

[2] Yahagi, T., Nagao, M., Hara, K., Matsushima, T., Sugimura, T. and Bryan, G. T.: Relationships between the carcinogenic and mutagenic or DNA-modifying effects of nitrofuran derivatives, including 2-(2-furyl)-3-(5-nitro-2-furyl) acrylamide, a food additive, Cancer Res., 34, 2266-2273, 1974

[3] McCann, J., Choi, E., Y Amasaki, E. and Ames, B. N.: Detection of carcinogens as mutagens in the Salmonella/ microsome test: Assay of 300 chemicals, Proc. Natl. Acad. Sci. USA, 72 , 5135-5139, 1975

[4] McCann, J. and Ames, B. N.: Detection of carcinogens as mutagens in the Salmonella/ microsome test: Assay of 300 chemicals: Discussion, Proc. Natl. Acad. Sci. USA, 73, 950-954, 1976

[5] Tamura, T., Fujil, A. and Kuboyama, N.: Pharmacological studies on mutagenicity 1. Analgesics and anti-inflammatory drugs and their derivatives, Jpn. J. Pharmacol., 30, 111, 1980

[6] King, C. M. and Olive, C. W.: Comparative effects of strain, species, and sex on the acyltransferase- and sulfotransferase-catalyzed activations of N-hydroxy-N-2fluorenylacetamide, Cancer Res., 35, 906-912, 1975

[7] Yamazoe, Y., Kamataki, T. and Kato, R.: Species difference in N-hydroxylation of a tryptophan pyrolysis product in relation to mutagenic activation, Cancer Res., 41, 45184522, 1981

[8] Bartsch, H., Malaveille, C., Camus, A. M., Martel-Planche, G., Brun, G., Hautefeuille, A., Sabadie, N., Barbin, A., Kuroki, T., Drevon, C., Piccoli, C. and Montesano, R.: Validation and comparative studies on 180 chemicals with S. typhimurium strains and V79 Chinese hamster cells in the presence of various metabolizing systems, Mutation Res., 76, 1-50, 1980

[9] Nohmi, T., Yoshikawa, K., Nakadate, M. and Ishidate, M.: Species difference in the metabolic activation of phenacetin by rat and hamster liver microsomes, Biochem. Biophys. Res. Commun., 110, 746-752, 1983

[10] KADA, T. and SADAIE, Y.: In vitro and host-mediated "Rec-assay" procedures for screening chemical mutagens, and phloxine, a mutagenic red dye detected, Mutation Res., 16, 165-174, 1972

[11] Ames, B. N., Lee, F. D. and Durston, W. E.: An improved bacterial test system for the detection and classification of mutagens and carcinogens, Proc. Natl. Acad. Sci. USA, 70, 782-786, 1973

[12] Ames, B. N., McCann, J. and Yamasaki, E.: Methods for detecting carcinogens and mutagens with the Salmonella/mammalian-microsome mutagenicity test, Mutation Res., 31, 347-364, 1975

[13] Tamura, T., Fujin, A. and Kuboyama, N.: Studies on mutagenicity 1. Discussion on the best experimental condition for "Rec-assay" method, Nihon Univ. Oral Sci., 6, 335-340, 1980 (in Japanese)

[14] Tsuruzaki, T., Watanabe, G. and Yamamoto, M.: The effects of aspirin and acetaminophen during pregnancy on chromosomal structure in rat fetuses, Jpn. J. Hyg., 37, 787-796, 1981 
(in Japanese)

[15] IтAmi, T. and Kanoh, S.: Studies on the pharmacological bases of fetal toxicity of drugs, (1) Relation of fetal toxicity and tissue concentration of acetylsalicylic acid with pyrogen in pregnant rats, Folia Pharmacol. Japon., 79, 357-367, 1982 (in Japanese)

[16] Slone, D., Siskind, V., Heinonen, O. P., Monson, R. R., Kaufman, D. W. and Shapiro, S.: Aspirin and congenital malformations, Lancet, 26, 1373-1375, 1976

[17] Bengtsson, U.: Phenacetin and renal pelvic carcinoma, Clin. Nephrol., 2, 123-126, 1974

[18] Tomatis, L., Agthe, C., Bartsch, H., Huff, J., Montesano, R., Saracci, R., Walker, E. and Wilbourn, J.: Evaluation of the carcinogenicity of chemicals: A review of the monograph program of the international agency for research on cancer, Cancer Res., 38, 877-885, 1978

[19] Johausson, S., Angervall, L., Bengtsson, U. and Wahlqvist, L.: Uroepithelial tumors of the renal pelvis associated with abuse of phenacetin-containing analgesics, Cancer, 33, 743-753, 1974

[20] Isaka, H., Yoshi, H., Kaneko, Y., Koike, M., Otsuji, A., Nagai, Y., Koura, M. and Sugiyasu, K.: Tumor induction in the rat by phenacetin, Proc. Jpn. Cancer Assoc., 36th Annual Meeting, 18, 1977 (in Japanese)

[21] Isaka, H., Yoshil, H., Otsuji, A., Koike, M., Nagai, Y., Koura, M., Sugiyasu, K. and Kanabayashi, T.: Tumors of Sprague-Dawley rats induced by long-term feeding of phenacetin, Gann, 70, 29-36, 1979

[22] Sugimura, T., Sato, S., Nagao, M., Yahagi, T., Matsushima, T., Seino, Y., Takeuchi, M. and Kawachi, T.: Fundamentals in Cancer Prevention, 191-215, Univ. of Tokyo Press, Tokyo, 1976

[23] Lijinsky, W., Conrad, E. and Bogart, R. V.: Carcinogenic nitrosamines formed by drugs/ nitrite interactions, Nature, 239, 165-167, 1972

[24] Lijinsky, W., TAylor, H. W., Snyder, C. and Nettesheim, P.: Malignant tumors of liver and lung in rats fed aminopyrine or heptamethyleneimine together with nitrite, Nature, 244, 176-177, 1973

[25] Arisawa, M., Fujiu, M., Suhara, Y. and Maruyama, H. B.: Differential mutagenicity of reaction products of various pyrazolones with nitrite, Mutation Res., 57, 287-296, 1978

[26] Kuboyama, N.: Studies on mutagenicity of sulpyrine and metabolites, Nihon Univ. J. Oral Sci., 12, 119-131, 1986 (in Japanese) 